\title{
INFLUENZAL MENINGITIS *
}

T. M. RIVERS, M.D. BALTIMORE

Meningitis produced by $B$. influen $\approx a e$, although not extremely common, occurs frequently enough to be of considerable interest. According to Dunn ${ }^{1}$ and $\mathrm{Neal}^{2}$ it ranks fourth in order among the types of purulent meningitis, as shown in Table 1 .

TABLE 1.-Incidence of Influenzal Meningitis

\begin{tabular}{|c|c|c|c|}
\hline Type of & Meningitis & Dunn's Figures & Neal's Figures \\
\hline Meningococcic. & 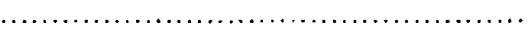 & 60 & 541 \\
\hline Pneumococeic... & 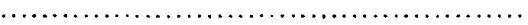 & 12 & 61 \\
\hline Streptococeic... & 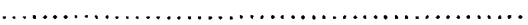 & 6 & 49 \\
\hline Influenzal...... & 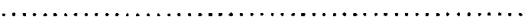 & 4 & 32 \\
\hline
\end{tabular}

In Baltimore, since 1913, at least twenty-three patients with influenzal meningitis have been seen, twenty of whom were on Dr. Howland's service in the Harriet Lane Home. Many of these cases were observed by me and I have already described ${ }^{3}$ the biologic and serologic reactions of influenza bacilli producing meningitis. It seemed advisable to report the twenty-three cases, review the literature and try to correlate the available facts about this disease which has caused so much discussion since its recognition.

The cases reported in this paper are summarized in Table 2 .

Table 3 contains a list of most of the authentic cases of influenzal meningitis on record. A number of such tables have been prepared by various workers. So many mistakes, however, were found in them that the original references have been consulted in nearly every instance. In that way the personal equation entering into the table has been limited to one person. Only infections of the meninges by $B$. influenzae alone are included in this series. When there is some doubt about the authenticity of the case, yet not enough to exclude it entirely, the fact is indicated.

Two hundred and twenty cases have been reported with seventeen recoveries (Tables 4, 5 and 6). The ages of 193 patients were given. Of these, 152 were under 2 years of age, forty-one were 2 years or older. Twelve of the seventeen recoveries, however, occurred in patients 2 years of age or older (Tables 5 and 6 ).

* Received for publication, March 30, 1922.

* From the Departments of Pathology and Bacteriology, and Pediatrics, Johns Hopkins University. 


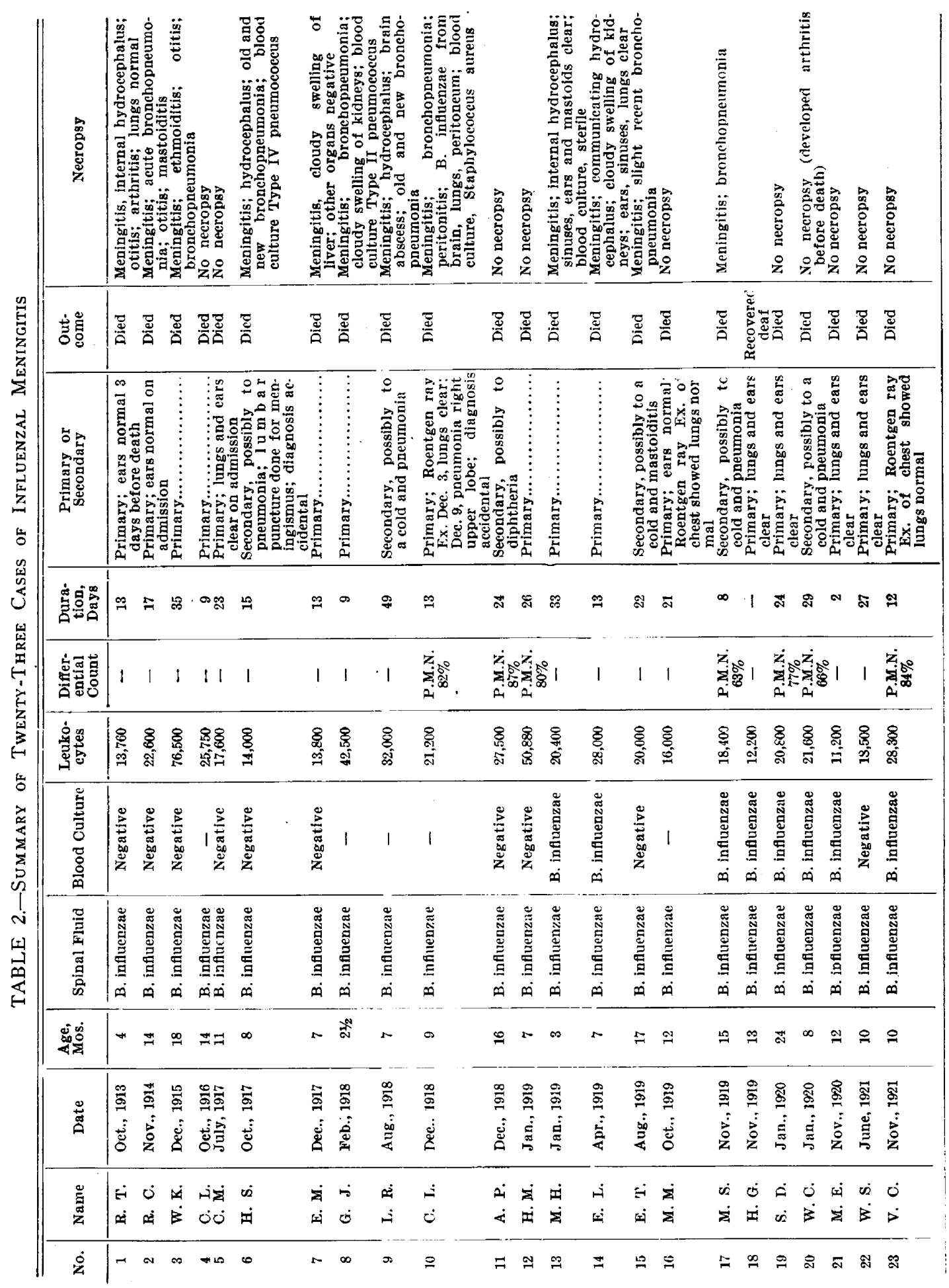


TABLE 3.-Authentic Cases of Influenzal Meningitis

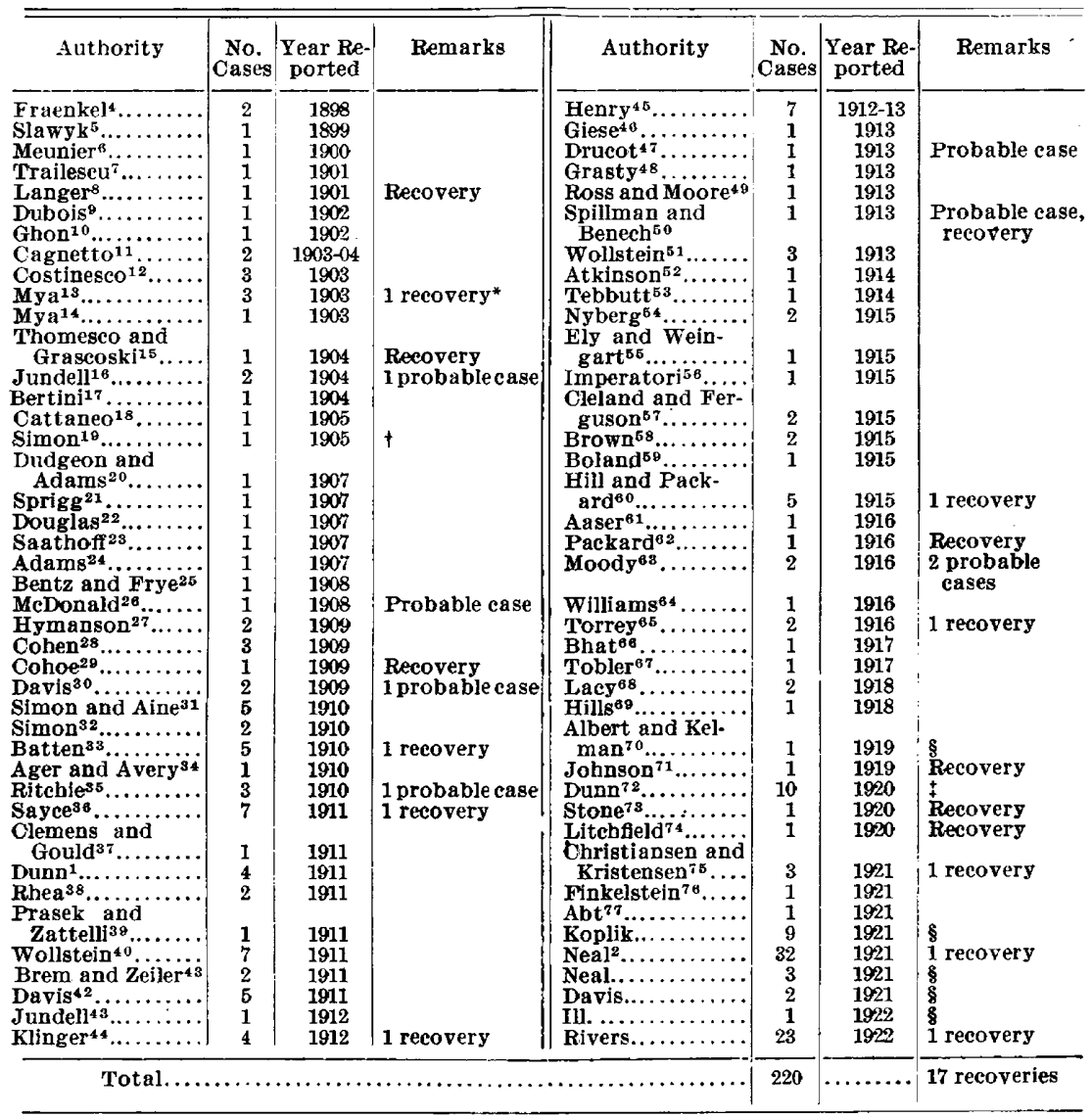

* One of these cases also reported by Caccia.

+ Reported also in 1902 and counted twice by Simon in 1910.

+ Eleven reported, but one included under Wollstein in 1913.

$\S$ Personal communication.

TABLE 4.-Mortality Rate

\begin{tabular}{|c|c|c|c|}
\hline Authority & $\begin{array}{c}\text { Number } \\
\text { Cases }\end{array}$ & $\begin{array}{c}\text { Number } \\
\text { Recovered }\end{array}$ & $\begin{array}{l}\text { Mortality, } \\
\text { per Cent. }\end{array}$ \\
\hline 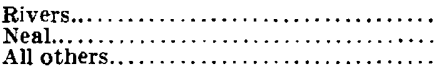 & $\begin{array}{r}23 \\
35 \\
162\end{array}$ & $\begin{array}{r}1 \\
1 \\
15\end{array}$ & $\begin{array}{l}96 \\
97 \\
91\end{array}$ \\
\hline Total $\ldots \ldots \ldots \ldots \ldots \ldots \ldots \ldots$ & 220 & 17 & 92 \\
\hline
\end{tabular}


TABLE 5--Relation of Age to Incidence and to Death or Recovery in One Hundred and Ninety-Three Cases in Which Age Was Stated

\begin{tabular}{|c|c|c|c|c|c|}
\hline Age & $\begin{array}{l}\text { Number } \\
\text { Cases }\end{array}$ & $\begin{array}{l}\text { Nurnber } \\
\text { Deaths }\end{array}$ & $\begin{array}{c}\text { Number } \\
\text { Recoveries }\end{array}$ & $\begin{array}{l}\text { Age Ineidence, } \\
\text { per Cent. }\end{array}$ & $\begin{array}{l}\text { Mortality, } \\
\text { per Cent. }\end{array}$ \\
\hline 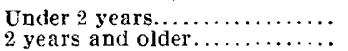 & $\begin{array}{r}152 \\
41\end{array}$ & $\begin{array}{r}147 \\
29\end{array}$ & $\begin{array}{r}5 \\
12\end{array}$ & $\begin{array}{l}79 \\
21\end{array}$ & $\begin{array}{l}97 \\
71\end{array}$ \\
\hline
\end{tabular}

TABLE 6.-List OF ReCoveries *

\begin{tabular}{|c|c|c|c|c|c|}
\hline No. & Authority & $\begin{array}{c}\text { Date } \\
\text { Reported }\end{array}$ & $\begin{array}{l}\text { Age of } \\
\text { Patient }\end{array}$ & $\begin{array}{l}\text { Duration } \\
\text { in Days }\end{array}$ & Sequels \\
\hline $\begin{array}{l}1 \\
2\end{array}$ & $\begin{array}{l}\text { Langer } \\
\text { Myais } \ldots \ldots \ldots \ldots\end{array}$ & $\begin{array}{l}1901 \\
1903\end{array}$ & $\begin{array}{l}9 \text { yrs. } \\
9 \text { mos. }\end{array}$ & 49 & $\begin{array}{l}\text { Residual left facial paralysis, residual left } \\
\text { hemiplegia }\end{array}$ \\
\hline 3 & $\begin{array}{l}\text { Thomeseo and } \\
\text { Grascoski15.... } \\
\text { Cohoe }^{29} \ldots \ldots \ldots\end{array}$ & $\begin{array}{l}1904 \\
1909\end{array}$ & $\begin{aligned} 7 & \text { yrs. } \\
33 & \text { yrs. }\end{aligned}$ & $\begin{array}{l}10 \\
15\end{array}$ & \\
\hline 5 & Batten ${ }^{33} \ldots \ldots \ldots$ & 1910 & 14 mos. & 30 & $\begin{array}{l}\text { Partial blindness, difficulty in sitting and } \\
\text { walking }\end{array}$ \\
\hline $\begin{array}{l}6 \\
7 \\
8\end{array}$ & $\begin{array}{l}\text { Sayce } 3 \theta \\
\text { Klinger } \\
\text { Spillman }\end{array}$ & $\begin{array}{l}1911 \\
1912\end{array}$ & $\begin{aligned} 4 & \text { yrs. } \\
26 & \text { yrs. }\end{aligned}$ & 60 & \\
\hline 9 & Hill and Pack- & 1913 & Adv. age & 14 & \\
\hline $\begin{array}{l}10 \\
11 \\
12\end{array}$ & 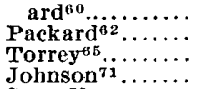 & $\begin{array}{l}1915 \\
1916 \\
1916 \\
1919\end{array}$ & $\begin{aligned} 4 & \text { mos. } \\
11 & \text { yrs. } \\
11 & \text { yrs. } \\
3 & \text { yrs. }\end{aligned}$ & $\begin{array}{l}20 \\
17 \\
20\end{array}$ & \\
\hline 13 & Stone $^{73} \ldots \ldots \ldots$ & 1920 & 15 yrs. & 11 & $\begin{array}{l}\text { Double optic neuritis with some residual } \\
\text { blindness; some residual involvement of } \\
\text { third nerve on one side }\end{array}$ \\
\hline 14 & $\begin{array}{l}\text { Litchfield }{ }^{74} \ldots \ldots \\
\text { Christiansen and } \\
\text { Kristensen }\end{array}$ & $\begin{array}{l}1920 \\
1921\end{array}$ & $\begin{array}{l}23 \text { mos. } \\
2 \text { yrs. }\end{array}$ & $\begin{array}{l}70 \\
23\end{array}$ & \\
\hline $\begin{array}{l}16 \\
17\end{array}$ & $\begin{array}{l}\text { Neal }^{2} \ldots \ldots \ldots \ldots \cdots \\
\text { Rivers............ }\end{array}$ & $\begin{array}{l}1921 \\
1922\end{array}$ & $\begin{array}{l}21 / 2 \text { yrs. } \\
13 \text { mos. }\end{array}$ & 30 & Complete nerve deafness \\
\hline
\end{tabular}

* Twelve of seventeen recoveries, 71 per cent, occurred in patients 2 years of age or older.

\section{CLINICAL' PICTURE}

The diagnosis of meningitis of all kinds is difficult in infants and young children. Influenzal meningitis is no exception. The 220 cases on record must be only a few of those diagnosed, and the number recognized does not necessarily include all that actually occurred. Batten ${ }^{33}$ agrees with me that many are overlooked.

There is no group of clinical findings peculiar to influenzal meningitis. At times it is indistinguishable clinically from epidemic cerebrospinal meningitis. A hemorrhagic rash ${ }^{2}$ even may be present which is supposed to be characteristic of the latter disease. It may simulate tuberculous meningitis, as an extreme bulging of the fontanel, paralysis of the eye muscles and irregular respirations (atypical Cheyne-Stokes) are frequently seen in patients living many days. Henry ${ }^{45}$ reported the spontaneous rupture of the fontanel in an infant 10 months of age. A strabismus was seen at some time in ten of my twenty-three patients. Paralysis of the face or extremities, arthritis, deafness and blindness occur in the order mentioned. The temperature may be elevated continuously or irregularly. Febrile periods may alternate with periods of 
normal temperature (see temperature charts accompanying the abstracts of case records). Influenzal meningitis is most commonly mistaken for pneumonia and this is probably due to an unexplained fever associated with rapid, difficult or embarrassed respirations.

White Blood Cell Count.-A leukocytosis with an increase in the percentage of the polymorphonuclear cells is usual (Table 7). Influenzal meningitis, a pure infection with Pfeiffer's bacillus, has an entirely different blood picture from the one seen in epidemic influenza which is accompanied by a leukopenia.

Table 7.-White Blood Cell Count in Influenzal Meningitis

\begin{tabular}{|c|c|c|c|c|c|c|}
\hline \multirow{3}{*}{$\begin{array}{c}\text { Authority } \\
\text { Rivers............. } \\
\text { All others........... }\end{array}$} & \multicolumn{4}{|c|}{$\begin{array}{l}\text { White Blood Cells } \\
\text { per C. Mm. }\end{array}$} & \multicolumn{2}{|c|}{$\begin{array}{l}\text { Per Cent. Polymorpho- } \\
\text { nuclear Cells }\end{array}$} \\
\hline & No. Cases & Low & High & Average & No. Cases & Average \\
\hline & $\begin{array}{l}23 \\
17\end{array}$ & 11,200 & $\begin{array}{l}76.500 \\
38.000\end{array}$ & 24,499 & $7^{7}$ & $\pi$ \\
\hline Total. .......... & 40 & 7,600 & 76,500 & 21,320 & 17 & 78 \\
\hline
\end{tabular}

The figures show that a polymorphonuclear leukocytosis is usually present in influenzal meningitis.

Blood Cultures.-In eighteen of my cases records of antemortem blood cultures are available (Table 2). Eight, or 44 per cent., were positive for $B$. influenzae. Most of the positive results were obtained from the patients listed in the last half of the table. So many negative results in the first half may have been due to inability to grow the bacilli when present. Records of antemortem and postmortem blood cultures were found in twenty-four instances in the review of the literature. Sixteen were positive for influenza bacilli.

Spinal Fluid.-Early in the disease the spinal fluid is slightly turbid with a ground-glass appearance. Usually polymorphonuclear cells predominate. Later the fluid may become so purulent and thick that it often flows with great difficulty or not at all through the needle. Batten ${ }^{33}$ believes that a very purulent fluid is more or less indicative of influenzal meningitis. Smears of the fluid practically always show many gram-negative pleomorphic bacilli, usually extracellular. No difficulty should be experienced in obtaining cultures of these bacilli when the proper medium is used. ${ }^{78}$ An indole test on the spinal fluid, as described by Rivers, ${ }^{79}$ is an aid in rapid diagnosis. While the bacilli are easily demonstrated in direct smears or in cultures by one accustomed to working with them, they may be overlooked by one less experienced. Consequently, some cases of influenzal meningitis may be treated as meningococcus infections in which no organisms were seen or grown and tabulated as deaths from epidemic cerebrospinal meningitis. 
Duration.-A false impression of the duration of the disease may be obtained from a few cases. Death may come quickly, in from twenty-four to thirty-six hours, or the patient may linger for days or months. Sayce ${ }^{36}$ reported that a child, 5 years old, lived six months after the diagnosis of influenzal meningitis had been established. Eighteen lumbar punctures were made at various times and B. infuenzae was isolated. At the necropsy these findings were confirmed. Many patients lived twenty, thirty, forty or sixty days. The average duration of the disease in thirty-two of Neal's patients was sixteen days; in Rivers' twenty-two cases, twenty days; in 112 cases, all others, eighteen days. The average for these three groups, comprising 166 patients, was eighteen days. The duration of the disease in the patients who recovered was given in thirteen instances (Table 6). The average was twenty-eight days.

Sequels.-Four of the seventeen recoveries were not complete (Table 6). Blindness, paralyses and deafness are the usual sequels.

\section{NECROPSIES}

The pathologic findings at necropsy depend a great deal on the duration of the disease before death. This is well illustrated by Rhea's ${ }^{38}$ two cases. The first patient was an infant 6 months old which died after an illness of three days. The necropsy revealed an acute hemorrhagic meningitis and encephalitis, an acute pharyngitis, laryngitis and bronchopneumonia. The heart's blood was sterile. A pure culture of influenza bacillus was obtained from the meninges and the bacilli were also seen in the exudate in the sections of the meninges. The encephalitis may explain some of the paralyses reported. The second

patient was a child 5 years of age which became sick suddenly. Influenza bacilli were obtained in pure culture from the spinal fluid and the blood. Before death, which came after an illness of eighty-nine days, a left hemiplegia and signs of hydrocephalus developed. An organizing meningitis with thickening and thrombosis of many of the blood vessels, and an internal hydrocephalus were found at necropsy. The ears, sinuses and lungs were normal. Cultures from the meninges and heart's blood remained sterile. These two cases are probably the extremes of the pathologic picture, which is usually one of a massive purulent meningitis. The exudate may collect at the base, along the vessels or in patches over the cortex. At times, the whole brain seems to be wrapped in a layer of pus $2 \mathrm{~mm}$. thick. Hydrocephalus is common. A brain abscess has been observed twice (Davis; ${ }^{42}$ Rivers). Bronchopneumonia is found in a large number of the patients. Otitis media, sinusitis, arthritis, peritonitis, nephritis and cloudy swelling of the liver and kidneys are some of the findings in other parts of the body. 


\section{ABSTRACTS OF CASE RECORDS}

Abstracts of eight case records are given to illustrate many points already mentioned and to emphasize others that will be considered later.

CASE 1 (1).-R. T., colored boy, 4 months old, became ill Oct. 20, 1913, with a "pain in the stomach" and loose bowels. These symptoms increased somewhat in severity until October 28 , when the mother noticed while bathing and dressing the child that the left shoulder was tender. There was no history of a cough, vomiting or convulsions. Drowsiness was noticed for the first time October 30. the day of admission to the hospital. The physical examination on admission showed a stiff neck, retracted head, hyperesthesia,

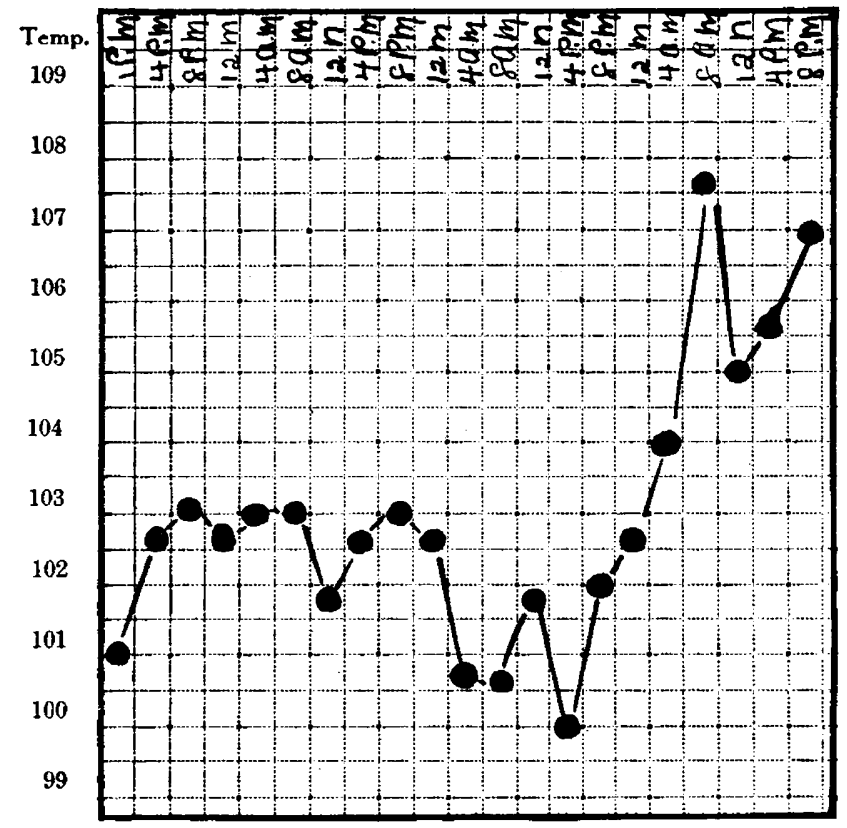

Fig. 1.-Temperature Chart for Case 1.

no discharge from the nose, normal ear drums, atypical Cheyne-Stokes respirations, normal lungs and heart, spastic paralysis of the left arm, no arthritis of the left shoulder or elbow, swelling of the left wrist and exaggerated deep reflexes. Kernig's sign was present. The white blood cell count was 13,760. The spinal fluid was cloudy. Gram-negative bacilli were seen in smears of the spinal fluid. Culturally these were influenza bacilli. The blood culture remained sterile. November 1 an internal strabismus of the right eye and a fluctuation in the swelling of the left wrist were noticed. A second blood culture made at this time also remained sterile. The patient died November 2, after an illness of thirteen days.

Anatomic Diagnosis (Necropsy 4015).-Fibropurulent cerebrospinal meningitis, internal hydrocephalus, suppurative otitis media (right), suppurative arthritis of left wrist, focal necrosis of liver, thrombosis of portal vein, pseudoinfarction of liver. 
Remarks.-The intern obtained no history of a respiratory infection preceding the illness. Intestinal symptoms predominated at the onset. After the diagnosis of influenzal meningitis was made, however, the resident managed to secure from the mother some kind of an indefinite history of a "cold" from which the child had suffered. The temperature chart would pass for that of a patient with tuberculous meningitis. No portal of entry was found at necropsy unless it were the otitis media, but the ear clrums were normal to otoscopic examination three days before death.

CASE 2 (5).-C. M., colored girl, 11 months old, refused to eat, had fever and held her head retracted, July 13, 1917. She would not use her right arm as before. Two days later the mother noticed a "cap" (bulging fontane1) on the bahy's head. The patient was admitted to the hospital July 17.

The physical examination on admission showed a conscious, irritable. hyperesthetic, rachitic child with a stiff neck and bulging fontanel, an internal

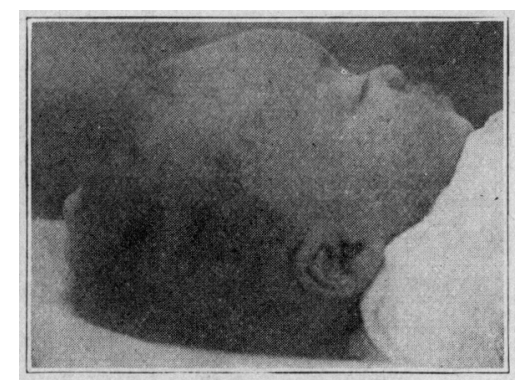

Fig. 2.-Photograph showing the bulging fontanel in Case 5.

strabismus of the left eye, no discharge from the nose, normal ear drums, and no definite signs of pneumonia. Kernig's sign was absent. The right arm was used less than the left. The white blood cell count was 17.600 . A tentative diagnosis of tuberculous meningitis was made. The spinal fluid was slightly turbid with a cell count of 750 per c. mm. About half of the cells were mononuclears. Films formed but no tulsercle bacilli were found. Other organisms were not looked for or were missed. Cultures were not made at this time. July 31 another lumbar puncture was made to search for tubercle bacilli. At this time gram-negative bacilli were seen and properly identified as $B$. influen a . Another examination of the spinal fluid, August 3, confirmed the diagnosis of influenzal meningitis. A blood culture made August 1 remained sterile. The respirations became irregular, atypical Cheyne-Stokes. Definite signs of pneumonia developed before death, which occurred August 5. A necropsy was not allowed.

Remarks.-This illustrates how easily influenzal meningitis can be mistaken for tuberculous meningitis. From the history and the course in the hospital nothing to which the meningitis could have been secondary was found. The pneumonia developed after the patient came into the hospital. 
CASE 3 (7).-E. M., white girl, 7 months old, refused to nurse Dec. 8, 1917. She remained in a stupor for twenty-four hours, after which she began to have convulsions. These convulsions, five or six a day, involved only the right side of the body and persisted until admission to the hospital, December 17. The mother noticed that the head was retracted December 16.

The physical examination on admission showed a retracted head, no discharge from the nose, slightly reddened ear drums, normal lungs, and constant twitchings of the right arm and leg. Kernig's sign was present. White blood cell count was 13,800 . The spinal fluid was cloudy and contained gram-negative bacilli which were influenza bacilli culturally. The blood culture remained sterile. Roentgen-ray examination of the lungs on the day of admission showed that they were practically normal. Temperature ranged between 101 and $103 \mathrm{~F}$. most of the time, but dropped nearly to normal before death. December 21 .
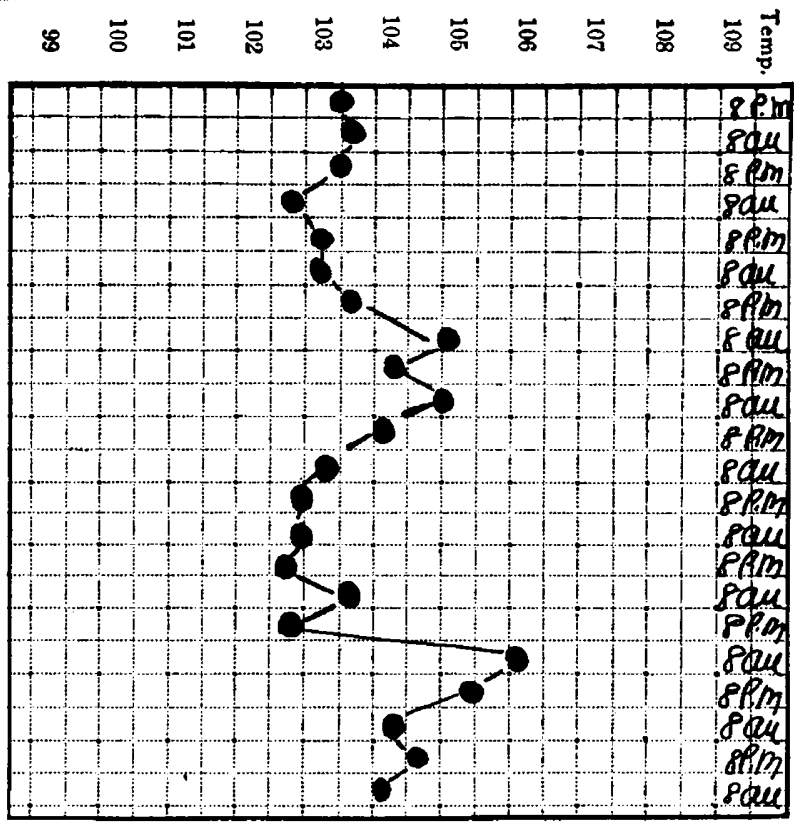

Fig. 3.-Temperature Chart for Case 5 .

Anatomic Diagnosis (Necropsy 5396). - Purulent cerebrospinal meningitis, cloudy swelling of the liver.

Remarks.-There is nothing in the history, physical examination, course in the hospital, or in the necropsy findings to suggest that this was anything other than a primary influenzal meningitis.

CASE 4 (8).-G. J., colored girl, 21/2 months old, became drowsy, refused to nurse and "rolled eyes up," Feb. 26, 1918. She gradually became worse and would scream when touched. March 4 the child began to have convulsions and was admitted to the hospital the next day.

The physical examination on admission showed a bulging fontanel, retracted head, stiff neck, internal strabismus of the left eve, no discharge from the nose or ears, few râles in the lungs. palpable spleen and exaggerated deep reflexes. Kernig's sign was present. White blood cell count was 42,500. The 
spinal fluid was cloudy and contained gram-negative bacilli which culturally were influenza bacilli. Patient died March 7.

Anatomic Diagnosis (Necropsy 5473).-Massive purulent cerebrcspinal meningitis, acute splenic tumor, cloudy swelling of the kidneys, bronchopneumonia, fibrous pleural adhesions (bilateral).

Necropsy Bacteriology.-Culture from meninges showed only B. influenzae. Culture from heart's blood showed only pneumococcus Type II.

Remarks.-The patient was afebrile while in the hospital. As far as can be determined, this is an example of a primary influenzal meningitis. Only small areas of bronchopneumonia were found in the lungs. The Type II pneumococcus found in the blood at the necropsy is interesting. Fixed types of pneumococci usually produce lobar pneumonia. They can, however, under the proper conditions act as secondary invaders and even cause bronchopneumonia.

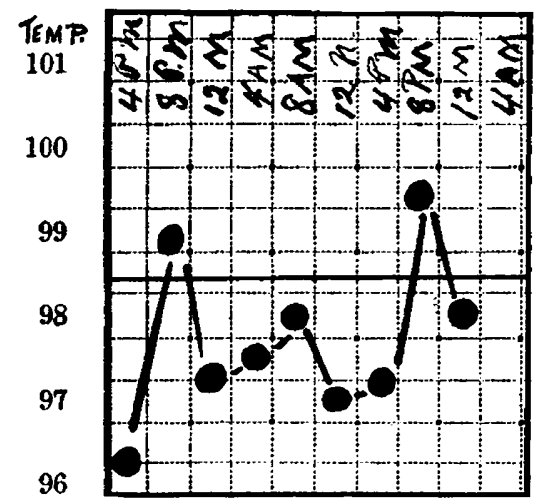

Fig. 4.-Temperature Chart for Case 8.

CASE 5 (12).-H. M., white female, 7 months old, became drowsy and feverish three weeks before admission to the hospital. At first there was a slight discharge from the nose. The family physician treated the baby for bronchitis in spite of the fact that she had no signs of it, not even a cough until a few days before coming to the hospital. One week before admission projectile vomiting after each feeding developed and three days before admission the head became retracted. The patient was admitted Jan. 21, 1919.

The physical examination showed a conscious, hyperesthetic baby with a stiff neck and a retracted head, no discharge from the nose or ears, anisocoria, indefinite signs of pneumonia in right interscapular region, exaggerated deep reflexes. White blood cell count was 50,880 . The spinal fluid was very thick and purulent. Gram-negative bacilli were seen in the smears. Culturally, these were influenza bacilli. The blood culture remained sterile. The child gradually became worse and began to have numerous convulsions before she died January 26. A necropsy was not allowed.

Remarks.-The child probably had a meningitis from the beginning. It was primary as far as can be determined. In spite of a purulent meningitis the temperature was normal for two days after admission to the hospital. The rise in temperature several days before death cannot be accounted for definitely. There are two possibilities, a 
terminal rise before death that is seen not infrequently in meningitis, or the development of a pneumonia.

CAse 6 (14).-E. L., white boy, 7 months old, became irritable April 4 , 1919. He gradually grew worse and would scream when touched or handled. Stiffness of his neck was noticed April 8, two days before admission to the hospital.

Physical examination when first seen showed a conscious child with a bulg: ing fontanel, retracted head and stiff neck, no discharge from the nose, normal ear drums, normal lungs, and paralysis of the right arm. Kernig's sign was absent. White blood cell count was 28,000 . The spinal fluid was cloudy. Gram-negative bacilli were seen in the smears. Culturally these were influenza bacilli. From the blood culture influenza bacilli were obtained also. April 10 it was noticed that the paralysis of the right arm had disappeared. The child gradually became worse. Before death, which occurred April 17, convulsions set in and an external strabismus of the right eye was seen.

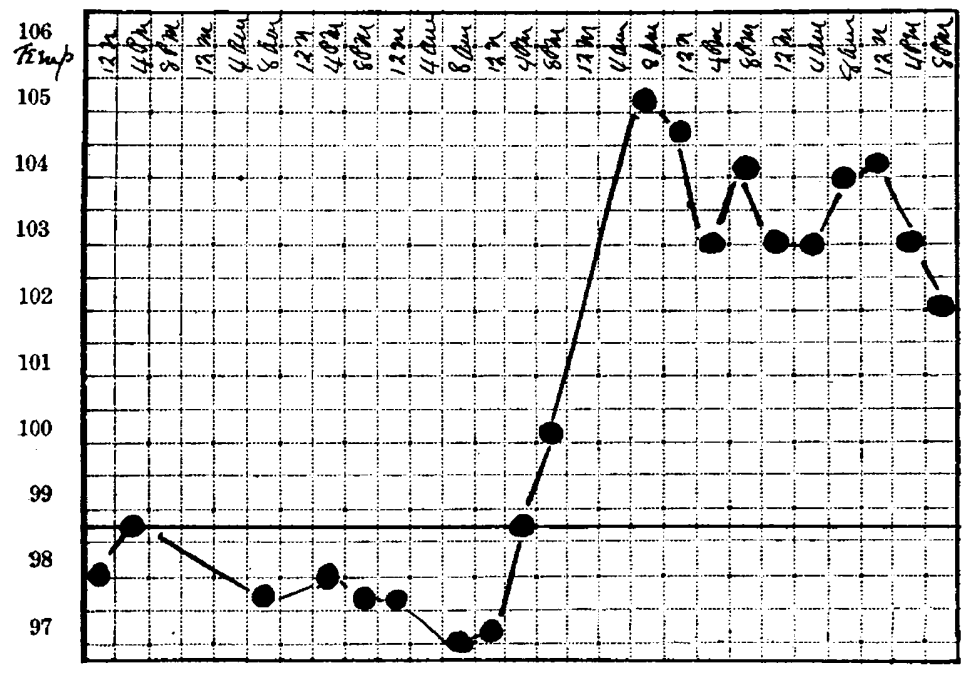

Fig. 5.-Temperature Chart for Case 12.

Anatomic Diagnosis (Necropsy 5880). - Purulent cerebrospinal meningitis, communicating hydrocephalus, cloudy swelling of the kidneys.

Remarks.-The ears, sinuses and lungs were normal while in the hospital and at necropsy. Influenza bacilli were obtained from the spinal fluid and blood during life and from the meninges and heart's blood at necropsy. The bacilli were pathogenic for rabbits.

CASE 7 (18).-H. G., white girl, 13 months old, became irritable and "droopy" Nov. 24, 1919. No history of vomiting, convulsions or rigidity was obtained. An internal strabismus of the left eye appeared November 26 , the day before the patient was brought to the hospital.

Physical examination showed a conscious, irritable, restless child that would not sit or stand as formerly, tense fontanel, internal strabismus of left eye, no discharge from the nose, normal ear drums, normal lungs. Kernig's sign absent. White blood cell count was 12,200. The spinal fluid was cloudy. Gram-negative bacilli were found in the smears. The organisms were 
B. influenzae culturally. Influenza bacilli were obtained from the blood culture. The patient was taken home November 28 . The child was a private patient of Dr. Hamburger. He reported later that she had recovered but was completely deaf.

Remarks.-There is nothing in the history, physical examination, or course of the disease to obviate the possibility that this might have been a primary influenzal meningitis. The organism was pathogenic for rabbits.

CASE 8 (19).-S. D., white girl, 2 years old, suddenly developed fever and irritability Jan. 13, 1920. Three days later the neck became stiff. An internal strabismus of the left eye was noted January 18, the day of admission to the hospital.

Physical examination on admission showed a conscious child that would answer questions, but had a stiff neck, internal strabismus of the left eye, no discharge from the nose, normal ear drums, normal lungs. Kernig's sign was present. White blood cell count was 20,800 . The spinal fluid was cloudy.

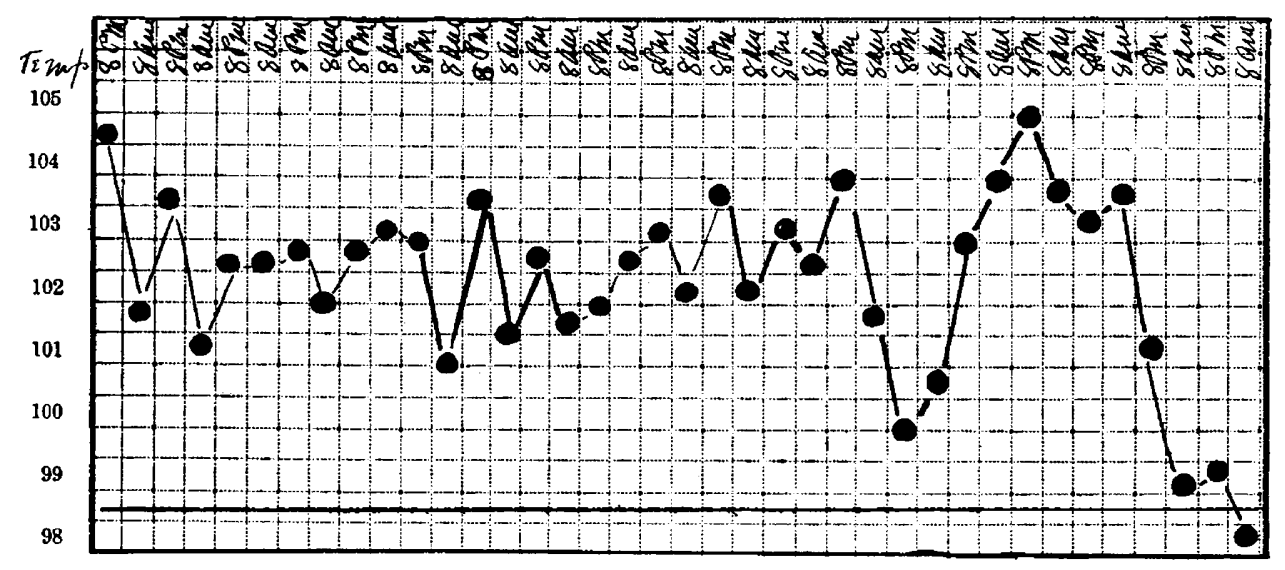

Fig. 6.-Temperature Chart for Case 19.

Gram-negative bacilli were seen in the smears. The organisms were $B$. influenzae culturally. Influenza bacilli were obtained from the blood culture. During the first twelve days in the hospital the patient did not seem very sick. She would eat, move around the bed and talk. Then she began gradually to become more ill until she died February 6 . The spinal fluid became so thick toward the last that it would not run through the needle. No signs of pneumonia were made out at any time. Six days before death the right ear drum became inflamed. A necropsy was not allowed.

Remarks.-This is another example, as far as can be determined, of a primary influenzal meningitis. The right ear drum became inflamed eleven days after the patient came to the hospital, about the time she became much worse and when under less favorable conditions the meningitis might have been recognized for the first time. No doubt many infections of the middle ear reported in connection with influenzal meningitis and thought of as possible portals of entry have occurred late in the course of an unrecognized meningitis. 
This clinical picture is well known. Nothing further can be gained by reporting cases as they occur. The main interest is centered around the question of whether influenzal meningitis is a primary or a secondary disease. No attempt will be made to tabulate all the ideas on the subject expressed by various workers. It seems they can be divided into three main groups. Under each of these will be given a few specific references.

\section{DIFFERENT CONCEPTIONS REGARDING NATURE OF INFLUENZAL. MENINGITIS}

1. Secondary to a Respiratory Infection.-Many clinicians thought and still believe that $B$. influenzae is the cause of epidemic influenza. Naturally these observers would conclude that influenzal meningitis is a complication of a respiratory infection. Wollstein ${ }^{40}$ and Dunn ${ }^{72}$ are of that opinion. Flexner ${ }^{80}$ said, "It is probable that the infection of the meninges is always secondary to the respiratory infection." Hill and Packard ${ }^{60}$ stated that the portal of entry was through the respiratory tract, secondary to influenza.

2. Part of a Generalized Infection.-Dudgeon and Adams ${ }^{20}$ considered the meningitis a part of a metastatic pyemic condition. Cohen 28 also thought that the meningitis was a part of a generalized infection. He believed, however, that this infection was caused by a definite group of organisms which he claimed differed from Pfeiffer's bacillus and called them Bacille méningite cérébrospinale septicémique.

3. A Primary Meningitis.-Klinger ${ }^{44}$ hinted that influenzal meningitis might be a primary idiopathic disease similar to epidemic cerebrospinal meningitis and was so bold as to suggest that the patients be isolated and that some kind of disinfection be observed in connection with them. Nyberg ${ }^{54}$ thought that one of his patients had a primary influenzal meningitis caused by one of a group of influenza bacilli having a predilection for the meninges.

The pathogenesis of influenzal meningitis will not be discussed in this paper further than to state that one's ideas in regard to it might vary, depending on whether it proves to be a primary or a secondary disease. Consequently all the evidence possible has been collected to determine whether any definite conclusions about the latter question can be reached.

\section{INFORMATION FROM HISTORIES AND NECRCPSIES}

Histories.-The records of cases of influenzal meningitis reported in the literature and of the twenty-three cases in my series have been analyzed to discover what evidence they may provide as to the primary or secondary nature of the disease. With the exception of Neal's ${ }^{2}$ thirty-two cases, my judgment is a large factor in Tables 8 and 9. 
Observers reporting cases have gone out of the way to find some preceding infection to which the meningitis might have been secondary. This is well illustrated by Case 1 in my series. In certain instances it is fairly eviclent that the meningitis was overlooked for a long time, often until after an otitis media, an arthritis, or a pneumonia had been found. In some instances, the minority, however, the meningeal infection was undoubtedly secondary, particularly to mastoiditis. Three of Henry's ${ }^{45}$ patients who were operated on for acute mastoid infections are good examples. Unfortunately, two of them have to be omitted as the meningitis was caused by two organisms-hemolytic streptococci and influenza bacilli. Other examples of secondary infections have been reported by Packard ${ }^{62}$ and Imperatori. ${ }^{56}$ In 171 instances (Table 8) it was possible from the history and course of the disease to form some opinion as to whether the meningitis was primary or secondary.

Table 8.-Division of One Hundred and Seventy-One. Cases, from Their Histories, Into Possible Primary and Possible Secondary Infections

\begin{tabular}{|c|c|c|c|c|c|}
\hline Authority & $\begin{array}{c}\text { Number } \\
\text { Cases }\end{array}$ & $\begin{array}{l}\text { Number } \\
\text { Primary }\end{array}$ & $\begin{array}{l}\text { Number } \\
\text { Secondary }\end{array}$ & $\begin{array}{l}\text { Per Cent. } \\
\text { Primary }\end{array}$ & $\begin{array}{l}\text { Per Cent. } \\
\text { Secondary }\end{array}$ \\
\hline 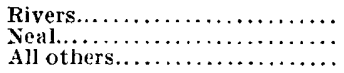 & $\begin{array}{r}23 \\
32 \\
116\end{array}$ & $\begin{array}{l}17 \\
24 \\
86\end{array}$ & $\begin{array}{r}6 \\
8 \\
30\end{array}$ & $\begin{array}{l}74 \\
75 \\
74\end{array}$ & $\begin{array}{l}26 \\
25 \\
26\end{array}$ \\
\hline Totals................. & 171 & 127 & 44 & 74 & 26 \\
\hline
\end{tabular}

Necropsies.-Bronchopneumonia was found in the majority of the cases at necropsy. Immediately the question arises as to whether the pneumonia was complicating the meningitis or vice versa. Bertini ${ }^{17}$ and Davis ${ }^{42}$ state that they could not be certain whether the pnetumonia antedated the meningitis in their cases or not. Giese, ${ }^{46}$ in reporting a case of influenzal meningitis, said that the meningitis was primary and that the slight pneumonia present was secondary. Torrey ${ }^{65}$ and Tobler ${ }^{67}$ suggested that the influenza bacilli pass from the cerebrospinal space into the circulation, giving rise to secondary infections in other organs. It is also possible that some of the pneumonia in these cases is caused by pneumococci or streptococci, similar to that occurring in children with dysentery or severe diarrheas. Christiansen and Kristensen ${ }^{75}$ reported that they recovered from the meninges of a patient dead of influenzal meningitis a pure culture of influenza bacilli and from the pneumonic consolidation in the lungs a pure culture of pneumococci. From two of my patients (Nos. 6 and 8) evidence was obtained that other bacteria might cause some of the complications found at necropsy. These patients had bronchopneumonia in addition to a meningitis. A pure culture of infuenza bacilli was obtained from the meninges of both cases, while from the heart's blood of one case 
a pure culture of a Type IV pneumococcus was recovered and from the heart's blood of the other a pure cuiture of a Type II pneumococcus was recovered. Unfortunately, cultures from the lungs were not made or the results were not recorded.

Necropsies were obtained in twelve of the twenty-two fatal cases in my series. In three of these twelve, 25 per cent., meningitis alone was found. The ears, sinuses, and lungs were normal. If there was a primary focus, it was overlooked or it had healed. The patients had been sick eleven, thirteen and thirty-three days, respectively. From the literature records of seventy-one necropsies, many of which were partial, have been examined. Often the findings in the brain were given without stating whether the other organs were normal or not examined. In spite of these difficulties, however, records of ten cases were seen in which a meningitis alone was found. The number of possible primary

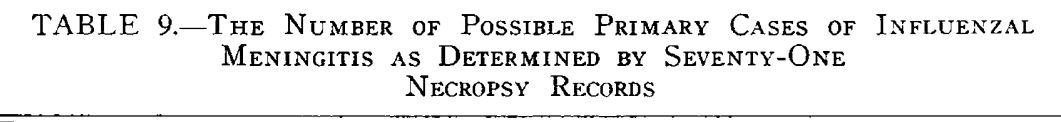

\begin{tabular}{|c|c|c|}
\hline No. Cases & Necropsy Findings & Per Cent. \\
\hline 10 & 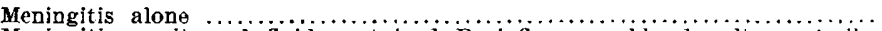 & 14 \\
\hline 1 & $\begin{array}{l}\text { Meningitis, peritoneal fluid contained } B \text {. influenzae, blood culture sterile, } \\
\text { lungs, ears, and sinuses normal }\end{array}$ & \\
\hline 1 & Meningitis, peritonjtis ( $\mathrm{B}$. influenzae), blood culture sterile, lungs normal & \\
\hline 3 & Meningitis, jungs normal & \\
\hline 2 & Meningitis, lungs and ears normal.... & 27 \\
\hline 3 & Meningitis, otitis media & \\
\hline 1 & Meningitis, pericarditis, endocarditis & \\
\hline 2 & Meningitis, arthritis & \\
\hline 1 & Meningitis, bronchopneumonia (pure culture pneumococcus) & \\
\hline 5 & $\begin{array}{l}\text { Meningitis, small patehes of bronchopneumonia which in some instances was } \\
\text { suggested as being secondary }\end{array}$ & \\
\hline 29 & 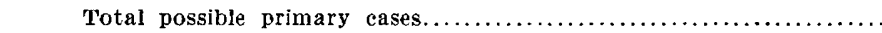 & 41 \\
\hline
\end{tabular}

cases of influenzal meningitis observed at necropsy are listed in Table 9. If these figures are correct, it would be easy to assume that many more were primary also, the pneumonia and other pathologic lesions complicating the meningitis.

Possibility of Spread by Carriers.-So few cases of influenzal meningitis occur that it is impossible to show that the disease is spread by contact. There are facts, however, that might make one think that it is spread by carriers. Many observers report several cases occurring within a short time of each other. Hill and Packard ${ }^{60}$ saw four cases in six months. Henry ${ }^{45}$ observed at least five cases in 1910. In Dr. Howland's clinic seven cases were seen in one year. Simon arid Aine, ${ }^{31}$ in reporting five cases, speak of them as a little epidemic of influenzal meningitis. Davis ${ }^{30}$ reported that twins 5 days old became ill at the same time, one died on the ninth day, the other on the twelfth. At the necropsy the first one was found to have had an influenzal meningitis. No lumbar puncture or necropsy was made in the second case. 
Although there may be some doubt about the second child having a meningitis, yet it is reasonable to suppose that it did, as it became ill at the same time and ran a course similar to the other. Davis ${ }^{42}$ also reported two cases of influenzal meningitis that occurred in a small institution of about fourteen inmates. The second child became ill two weeks after the death of the first. While not convincing, the evidence is at least suggestive that influenzal meningitis is a carrierborne disease.

Incubation Period.-Enough information is not available to draw any conclusions in regard to the length of the incubation period. In the case of Davis' twins, however, one can be certain that the incubation period was not longer than five days.

Yearly Incidence of Influen al Meningitis.- Jordan ${ }^{81}$ and Neal ${ }^{2}$ have commented on the fact that there was no great increase in influ-

TaBle 10.-Yearly Incidence of Two Hundred and Three Cases of INFLUENZAL MENINGITIS

\begin{tabular}{|c|c|c|c|c|c|c|c|}
\hline \multirow[b]{2}{*}{ Year } & \multicolumn{3}{|c|}{ Number of Cases } & \multirow[b]{2}{*}{ Year } & \multicolumn{3}{|c|}{ Number of Cases } \\
\hline & $\begin{array}{c}\text { Year } \\
\text { Stated }\end{array}$ & $\underset{\text { Year Ap- }}{\text { proximated }}$ & Total & & $\begin{array}{l}\text { Year } \\
\text { Stated }\end{array}$ & $\begin{array}{l}\text { Year Ap- } \\
\text { proximated }\end{array}$ & Total \\
\hline 1897 & 2 & 0 & 2 & 1910 & 21 & ij & 27 \\
\hline 1898 & 0 & 0 & 0 & 1911 & 6 & $\underline{\underline{y}}$ & 8 \\
\hline 1899 & 2 & $\mathbf{1}$ & 3 & 1912 & 9 & 2 & 11 \\
\hline 1900 & 0 & 0 & 0 & 1913 & 5 & $\overline{2}$ & 7 \\
\hline 1001 & 0 & 2 & 2 & 1914 & 9 & $\overline{0}$ & 9 \\
\hline 1902 & 8 & 3 & 11 & 1915 & 11 & 4 & 15 \\
\hline 1903 & $\stackrel{\circ}{2}$ & 3 & 5 & 1916 & 9 & $\begin{array}{l}\mathbf{x} \\
\mathbf{0}\end{array}$ & 9 \\
\hline 1904 & 0 & 0 & 0 & 1917 & 12 & 0 & 12 \\
\hline 1905 & 1 & 1 & 2 & 1918 & 12 & 0 & 12 \\
\hline 1906 & $\frac{1}{3}$ & 0 & 5 & 1919 & 18 & 0 & 18 \\
\hline 1907 & 10 & 0 & 10 & 1920 & 10 & 0 & 10 \\
\hline 1908 & 8 & 0 & 8 & 1921 & 6 & 0 & 6 \\
\hline \multirow{2}{*}{\multicolumn{2}{|c|}{$\begin{array}{l}\text { IS09 } \\
\text { Total. }\end{array}$}} & 7 & 13 & $10-1$ & - & - & -1 \\
\hline & & $\ldots \ldots \ldots \ldots$ & $\ldots \ldots \ldots$ & $\ldots \ldots \ldots$ & 170 & 33 & $=03$ \\
\hline
\end{tabular}

enzal meningitis during and after the pandemic of influenza in 1918. This was used to show that there is no definite relationship between the etiology of the two diseases. Table 10 and Figure 7 give the incidence of influenzal meningitis by years in 203 instances where the year was stated or could be approximated.

Regardless of the etiology of epidemic influenza it would be difficult for one to deny an increased prevalence of $B$. influenzae during the last pandemic of that disease. With this increased prevalence of influenza bacilli and with so much disease of the respiratory tract there should have been a decided increase in the number of cases of influenzal meningitis if the ordinary respiratory strains of $B$. influenzae were the usual cause of the latter disease. From Table 10 and Figure 7 it is evident that there was no marked general rise in the number of cases. In Chicago, according to Jordan ${ }^{81}$ and Davis, ${ }^{82}$ there was practically no influenzal meningitis. In New York, according to Neal, ${ }^{2}$ only one 
case occurred during the epidemic of influenza in the autumn of 1918 . There was, however, a slight rise in the number of cases for 1916, 1917, 1918 and 1919. In Baltimore, on the other hand, there was a decided increase during 1917, 1918, 1919 and 1920 (Fig. 7). In spite of this increase in the number of cases, no definite relationship between

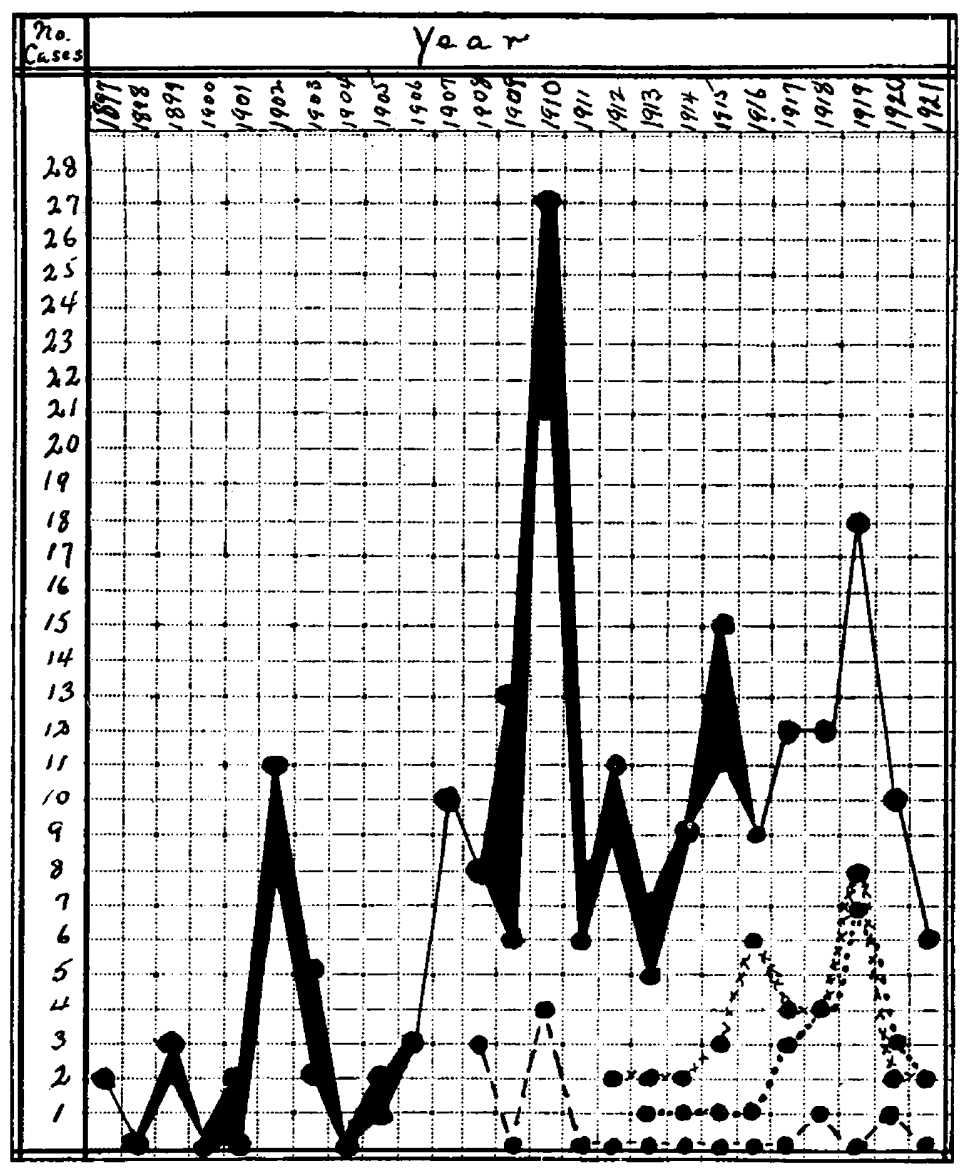

Fig. 7.-The unbroken line shows the yearly incidence of 203 cases of influenzal meningitis. The lower level of the shaded areas represents the number of cases that were stated as occurring in that year, the upper level represents the above cases plus the ones in which the year of occurrence was approximated. - - - , yearly incidence in Chicago of cases seen by Davis; ........, yearly incidence of Rivers cases in Baltimore; $\mathrm{x} \times \mathrm{x}$, yearly incidence of Neal's cases in New York City.

influenza and influenzal meningitis can be discovered as the majority of the cases of the latter disease did not occur during the epidemics of the former. All one can say is that in different localities there is a fluctuation in the number of cases of influenzal meningitis from year to year and that this fluctuation is not dependent on epidemic influenza. 
The year of occurrence can be approximately stated in 203 instances of influenzal meningitis (Table 10 and Fig. 7). The striking thing is that the greatest number in one year was in 1910 when the world was exceptionally free of epidemic and interepidemic influenza. ${ }^{83} \mathrm{~A}$ possible explanation for this will be apparent when the biologic and the serologic reactions of the meningitic and respiratory strains of $B$. infuenzae are compared.

Seasonal Incidence of Influenzal Meningitis.-The month of occurrence of the cases of influenzal meningitis was stated in 126 instances. Most of them were in October, November, December and January (Fig. 8). 'In Baltimore pneumonia is more prevalent after Christmas, while influenzal meningitis (Fig. 8) occurs more frequently during the months just before Christmas, prior to the pneumonia season. In New York the majority of Neal's ${ }^{2}$ cases occurred also during the months of October, November, and December (Fig. 8). Holt ${ }^{84}$ has pointed out that in New York the curve of tuberculous meningitis, plotted by months, follows the curve of deaths from pneumonia (Fig. 8). The peaks of these curves come well after Christmas, in March and April. The etiology of tuberculous meningitis cannot be confused with that of ordinary pneumonia. Holt suggested that the curves parallel each other because acute respiratory diseases cause an exacerbation and a dissemination of tuberculosis. On the other hand, the curve of infuenzal meningitis, which has been considered by many to be secondary to acute respiratory infections, does not follow the curve of deaths from pneumonias as closely as does tuberculous meningitis (Fig. 8).

Biologic and Serologic Reactions of Different Influenza Bacilli-If influenzal meningitis be a primary disease in most instances, one would expect to find a close relationship culturally and serologically between the strains producing it. Povitsky and Denny ${ }^{85}$ demonstrated that four of seven meningitic strains were identical by absorption of agglutinin tests. Rivers and Kohn, ${ }^{3}$ working with thirteen strains of influenza bacilli isolated from the meninges or the spinal fluids of patients with influenzal meningitis, showed that eleven were alike culturally. These eleven strains were closely allied, as shown by agglutination tests. By absorption of the agglutinin test two main groups were found: Group I of seven strains; Group II of three strains, an intermediate group of one strain. At that time four blood culture strains isolated from children with pneumonia following influenza were studied also. These were found to be different from each other and from the meningitic strains. Since the publication of that paper two more meningitic strains have been studied, one of which fell into Group I, the other was identical with none of the other strains. This grouping of the meningitic strains is especially marked in distinc- 
tion to the apparent heterogeneity of the respiratory strains as shown by Valentine and Cooper, ${ }^{86}$ Povitsky and Denny, ${ }^{85}$ Chesney, ${ }^{87}$ and others.

I have compared the meningitic strains with fourteen respiratory ones other than the four blood culture strains already mentioned. In no instance was any one of the respiratory strains identical with the meningitic strains serologically, even when they had similar cultural characteristics. If influenzal meningitis proves to be a carrier-borne

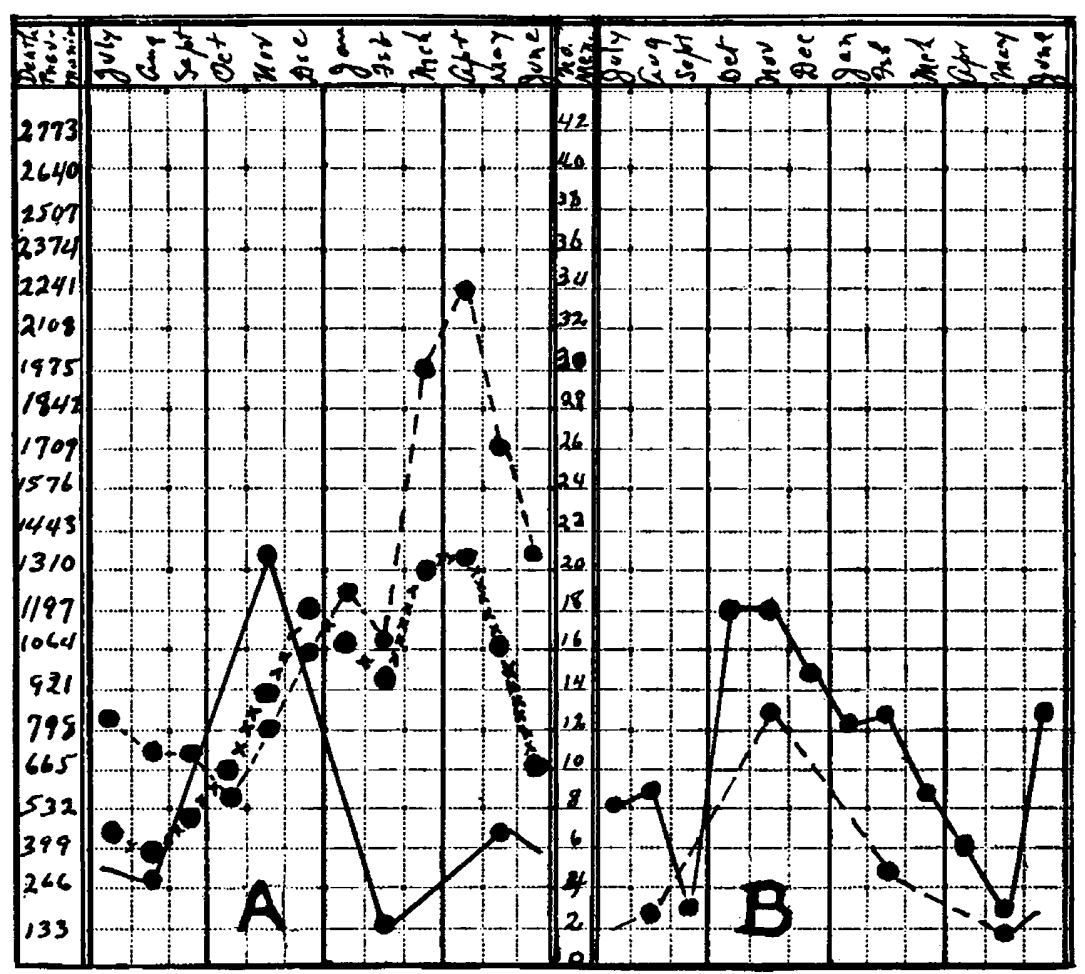

Fig. 8. A. $x \times x \times$, seasonal incidence of deaths from pneumonia in New York City for one year. - - - , seasonal incidence of 218 cases of tuberculous meningitis in New York City. ——, seasonal incidence of thirty-five cases of influenzal meningitis in New York City. The two upper curves were copied from Holt. ${ }^{84}$ The lower curve was plotted from Neal's ${ }^{2}$ figures.

B. , seasonal incidence of 126 cases of influenzal meningitis. _____, seasonal incidence of Rivers' twenty-three cases of influenzal meningitis.

disease, however, meningitic strains will be found eventually in throat cultures. In all, fifteen meningitic strains have been studied, eight of which were in Group I, three in Group II, one intermediate, and three heterogeneous strains. Of eighteen respiratory strains none was found identical with the meningitic strains. These results are summarized in Table 11. 
From four of the patients with a meningitis blood culture strains were obtained and studied also. These were found to be identical with the corresponding meningeal strains. This is contrary to the findings of Anderson and Schultz, ${ }^{88}$ who reported that the meningeal and the blood culture strains from the same patient were different immunologically.

The fact that most of the meningitic strains of $B$. influenzae are different from the respiratory ones probably accounts for the absence of a marked increase in the prevalence of influenzal meningitis during the pandemic of influenza when influenza bacilli were plentiful in diseased respiratory tracts.

Relatice Pathogenicity of Meningeal and Respiratory Strains.Cohen, ${ }^{28}$ and Cohen and Fitzgerald ${ }^{89}$ were among the first to suggest that $B$. infuen $\sim a \mathcal{C}$ from patients with meningitis differed from ordinary

TABLE 11.-Summary of the Biologic and the Serologic Reactions of Fifteen Meningitic and Eighteen Respiratory Strains OF B. INFLUENZAE

\begin{tabular}{|c|c|c|c|c|c|c|c|c|}
\hline \multirow[b]{2}{*}{$\begin{array}{l}\text { No. Strains } \\
\text { Meningitic }\end{array}$} & \multicolumn{5}{|c|}{ Biologic Reactions } & \multicolumn{3}{|c|}{$\begin{array}{l}\text { Groups Determined by } \\
\text { Absorption Tests }\end{array}$} \\
\hline & $\begin{array}{c}\text { Nitrate } \\
\text { Reduction }\end{array}$ & Indol & Glucose & Xvlose & Maltose & Group & Inter- & Group \\
\hline 8 & $\div$ & + & + & + & - & + & - & -. \\
\hline 1 & $\div$ & + & + & + & - & - & + & - \\
\hline 3 & $\div$ & + & + & + & - & - & - & + \\
\hline 1 & + & - & + & + & - & - & - & - \\
\hline 1 & - & $\tau$ & + & - & - & - & - & - \\
\hline 1 & + & t & - & - & - & - & - & - \\
\hline \multicolumn{9}{|l|}{ Respiratory } \\
\hline 7 & + & + & + & + & - & - & - & - \\
\hline 4 & + & + & + & -. & - & - & - & - \\
\hline 5 & + & - & + & + & - & - & - & - \\
\hline 1 & + & - & + & + & + & - & - & - \\
\hline 1 & + & - & + & - & + & - & - & - \\
\hline
\end{tabular}

+ indicates nitrates are reduced and indol is formed; - indicates the oppposite. Under the sugars + indicates acid is formed without gas; - indicates neither acid nor gas is formed. under grouping + indicates into which group the strains fall; - - indicates that the strains do not belong to that group.

respiratory influenza bacilli. They based their conclusions on results of agglutination tests, protection experiments, and on the fact that the meningitic strains were highly pathogenic for rabbits. Wollstein, ${ }^{40}$ from her studies concluded that respiratory and meningeal strains of $B$. infuenzae were more or less identical culturally and immunologically, varying only in virulence. ${ }^{90}$ She ${ }^{51}$ has shown conclusively, however, that there is a difference between the two groups in the pathogenicity for rabbits. Of seventy respiratory strains only four were pathogenic for rabbits, while eight of nine meningitic strains were pathogenic. Davis ${ }^{42}$ failed to find any difference in the virulence of respiratory and meningeal strains. Other observers have usually found the meningeal strains pathogenic for small animals, especially rabbits. Henry ${ }^{45}$ isolated from one of his patients with influenzal meningitis a bacillus that was nonpathogenic for laboratory animals. He obtained pathogenic bacilli, however, from some of his other patients. The nonpathogenic 
organism was isolated from a patient with a meningitis following a mastoiditis for which an operation was done. At the necropsy the meningitis was localized mostly at the base and on the side of the brain near the site of operation. Perhaps this was an instance of a secondary meningitis produced by an ordinary respiratory strain of $B$. influen $\approx \alpha e$. In that event the bacillus would be expected to have the pathogenicity as well as the serologic reactions of an ordinary respiratory strain. I have tested the pathogenicity of five meningeal strains and found that all of them, when first isolated, killed rabbits in small intravenous doses. The few respiratory strains so far tested have failed to do so.

\section{DISCUSSION}

The facts in this paper are not presented as conclusive evidence that influenzal meningitis in the majority of instances is a primary disease. They are suggestive enough, however, to indicate that such may be the case and to show how the disease should be thought of and studied in the future. The idea that it is a primary disease caused by the special group of $B$. infuenzae does not exclude the possibility that it may at times be secondary and produced by ordinary respiratory strains of influenza bacilli, nor does it exclude the possibility that the meningitic strains may occasionally produce diseases other than meningitis.

Treatments of various kinds have been used, but as far as can be determined none has accomplished much. Even the serum ${ }^{72}$ produced by Wollstein ${ }^{91}$ has not given the results expected. ${ }^{51}$ It may be, since more is now known of the biologic and the serologic reactions of meningitic strains of influenza bacilli, that a better treatment serum can be produced.

\section{SUMMARY}

The records of 197 cases of influenzal meningitis have been reviewed and twenty-three new cases are reported.

Influenzal meningitis is a disease of infancy, 79 per cent. of cases occurring in patients under 2 years of age.

The mortality in 220 cases was 92 per cent. Of the seventeen patients who recovered twelve were 2 years of age or older.

There is no typical clinical picture of influenzal meningitis. Many cases are probably overlooked.

There is usually a polymorphonuclear leukocytosis.

From the case records it is possible to say that the meningitis might have been primary in the majority of instances.

Influenzal meningitis is probably a carrier-borne disease.

The seasonal and yearly incidence of influenzal meningitis and of epidemic influenza and pneumonia do not coincide.

The meningitic strains of influenza bacilli are closely allied to each other and differ from the ordinary respiratory strains of $B$. infucenzae, 
particularly in their serologic reactions and in their pathogenicity for rabbits.

\section{CONCLUSIONS}

Influenzal meningitis appears to be in most instances a primary disease produced by a group of influenza bacilli which are closely allied culturally and serologically. ${ }^{92}$

\section{BIBLIOGRAPHY}

1. Dunn, C. H.: Am. J. Dis. Child. 1:95 (Jan.) 1911.

2. Neal, J. B.: Arch. Pediat. 38:1, 1921.

3. Rivers, T. M., and Kohn, L. A.: J. Exper. M. 34:477, 1921.

4. Fraenkel, E.: Ztschr. f. Hyg. 27:315, 1898.

5. Slawyk: Ztschr. f. Hyg. 32:443, 1899.

6. Meunier, H.: Compt. rénd. Soc. de biol. 52:5, 1900.

7. Träilescu, I: Spitalul Rev. Med. 21:474, 1901.

8. Langer, J.: Jahrb. f. Kinderh. 53:91, 1901.

9. Dubois: Thèse de Paris, Nov. 27, 1902, No. 49. Cited by Adams: Arch. Pediat. 24:721, 1907.

10. Ghon, A.: Wien. klin. Wchnschr. 15:667, 1902.

11. Cagnetto, G.: Atti d. Reale Inst. Veneto 63: Pt. 2, 397, 1903.

12. Costinesco: Congress Internat. d. Med., 1903, Pediat. Sec., p. 967.

13. Mya, G.: Gaz. d. 'Osp. 24:268, 1903.

14. Mya: Riv, clin. Pediat. 1:465, 1903.

15. Thomesco and Grascoski: Bull. de la Soc. des Sc. Méd. de Bucharest, 1904, No. 2. Abstracted: Rév. neurol. 13:44, 1905.

16. Jundell, I.: Jahrb. f. Kinderh. 59:777, 1904.

17. Bertini, E.: Riv. clin. Pediat. 2:673, 1904.

18. Cattaneo, C.: Rend. d. Assn. med.-chir. di Parma 6:115, 1905. Alstr. Centralbl. f. Bakteriol. (Ref.) 39:455, 1907.

19. Simon, G. L.: Rev. mens. d. mal. de l'enf. $23: 271,1905$.

20. Dudgeon, L. S., and Adams, J. E.: Lancet 2:684, 1907.

21. Sprigg, W. M.: Am. J. Obst. 56:467, 1907.

22. Douglas, J. Sh. C.: Lancet 1:86, 1907.

23. Saathoff : München. med. Wchnschr. 54:2220, 1907.

24. Adams, S. S.: Arch. Pediat. 24:721, 1907.

25. Bentz, C. A., and Frye, M. J.: Woman's M. J. 18:73, 1908.

26. McDonald, S.: J. Path. \& Bacteriol. 12:442, 1908.

27. Hymanson, A.: New York M. J. 90:1268, 1909.

28. Cohen: Ann. de l'Inst. Pasteur 23:273, 1909.

29. Cohoe, B. A.: Am. J. M. Sc. 137:74, 1909.

30. Davis, D. J.: Arch. Int. Med. 4:323 (Sept.) 1909.

31. Simon and Aine: Semaine méd. 30:513, 1910.

32. Simon, G.: Monatschr. f. Kinderh. 9:549, 1910.

33. Batten, F. E.: Lancet 1:1677, 1910.

34. Ager, L. C., and Avery, O. T.: Arch. Pediat. 27:284, 1910.

35. Ritchie, J.: J. Path. \& Bacteriol. 14:615, 1910.

36. Sayce, O. A.: Australian M. J. 16:25, 1911.

37. Clemens, J. R., and Gould, C. W.: Arch. Pediat. 28:210, 1911.

38. Rhea, L. J.: Arch. Int. Med. 8:133 (July) 1911.

39. Prasek, E., and Zatelli, T.: Wien. klin. Wchnschr. 24:932, 1911.

40. Wollstein, M.: Am. J. Dis. Child. 1:42 (Jan.) 1911.

41. Brem, W. V., and Zeiler, A. H.: Am. J. Dis. Child. 1:417 (June) 1911.

42. Davis, D. J.: Am. J. Dis. Child. 1:249 (March) 1911. 1912.

43. Jundell, I.:., Hygiea Medicinsk och Farmaceutisk Månadsskrift 74:326,

44. Klinger, R.: Cor.-B1. f. schweiz. Aerzte 42:1289, 1912.

45. Henry, H.: J. Path. \& Bacteriol. 17:174, 1912.

46. Giese, H.: Ugesk. f. Læger 75:621, 1913. 
47. Ducrot: Rev. Méd. de la Franche-comité 21:195, 1913.

48. Grasty, T. S. D.: Am. J. Obst. 67:1031, 1913.

49. Ross, A., and Moore, A. E.: Brit. M. J. 2:1056, 1913.

50. Spillman, P., and Benech, J.: Province méd. 24:433, 1913. 1913.

51. Wollstein, M.: Tr. Fifteenth Internat. Congr. Hyg. and Demog. 2:57,

52. Atkinson, E.: M. J. Australia 1:421, 1914.

53. Tebbutt, A. H.: M. J. Australia 1:415, 1914.

54. Nyberg, C.: Finska Läk.-Sällsk. Handl. 57:1369, 1915.

55. Ely, F. A., and Weingart, J.: J. Iowa State M. S. 5:391, 1915.

56. Imperatori, C. J.: Laryngoscope 25:580, 1915.

57. Cleland, J. B., and Ferguson, E. W.: M. J. Australia 1:308, 1915.

58. Brown, A.: Canad. M. A. J. 5:1077, 1915.

59. Boland, C. V.: Lancet 2:704, 1915.

60. Hill, R. B., and Packard, R. J.: Lancet-Clinic 113:723, 1915.

61. Aaser, E.: Tidsskr. f. d. norske Lægefor. 36:393, 1916.

62. Packard, F. R.: Ann. Otol., Rhinol. \& Laryngol. 25:706, 1916.

63. Moody, E. E.: J. Missouri State M. A. 13:328, 1916.

64. Williams, E. H.: New Zealand M. J. 15:48, 1916.

65. Torrey, R. G.: Am. J. M. Sc. 152:403, 1916.

66. Bhat, K. S.: Lancet 2:384, 1917.

67. Tobler, W.: Cor.-B1. f. schweiz. Aerzte 47:881, 1917.

68. Lacy, G. R.: J. Lab. \& Clin. M. 4:2, 55, 1918.

69. Hills, R.: New York M. J. 107:345, 1918.

70. Albert, H., and Kelman, S.: J. Infect. Dis. 25:433, 1919.

71. Johnson, C. K.: Arch. Pediat. 26:82, 1919.

72. Dunn, C. H.: Pediatrics 3:547, 1920.

73. Stone, C. T.: Texas State J. M. 15:318, 1920.

74. Litchfield, W. F.: M. J. Australia 1:104, 1920.

75. Christiansen, M., and Kristensen, M.: Ugesk. f. Læger 83:551, 1921.

76. Finkelstein, H.: Lehrbuch der Säuglingskrankh., Ed. 2, Berlin, 1921, p. 571.

77. Abt, I. A., and Tumpeer, I. H.: Am. J. Dis. Child. 21:444 (Nov.) 1921.

78. Rivers, T. M.: Bull. Johns Hopkins Hosp. 30:129, 1919.

79. Rivers, T. M.: J. A. M. A. 75:1495 (Nov. 27) 1920.

80. Flexner, S.: J. A. M. A. 67:16 (July 3) 1911.

81. Jordan, E. O.: J. A. M. A. 74:623 (Feb. 28) 1920.

82. Personal Communication.

83. Jordan, E. O.: Interepidemic Influenza, De Lamar Lecture, School of Hygiene, Johns Hopkins University, Jan. 31, 1922.

84. Holt, L. E.: Am. J. Dis. Child. 1:26 (Jan.) 1911.

85. Povitsky, O. R., and Denny, H. T.: J. Immunol. 6:65, 1921.

86. Valentine, E., and Cooper, G. M.: J. Immunol. 4:359, 1919.

87. Chesney, A. M.: J. Infect. Dis. 29: 132, 1921.

88. Anderson, R. A., and Schultz, O. T.: J. Exper. M. 33:653, 1921.

89. Cohen, Ch., and Fitzgerald, J. G.: Centralbl. f. Bakteriol. 56:464, 1910.

90. Wollstein, M.: J. Exper. M. 22:445, 1915.

91. Wollstein, M.: J. Exper. M. 14:73, 1911.

92. After the completion of this paper Dr. I. H. Erb furnished information concerning nine cases of influenzal meningitis observed in the Hospital for Sick Children in Toronto in the last two and one-half years. Of the nine patients seven were under 2 years of age. One case occurred in September and three cases in November, 1919; one in November and one in December, 1920; two in November and one in December, 1921. The mortality was 100 per cent. A necropsy was obtained in every instance and the meningitis was considered to have been primary in four of the nine patients, 44 per cent. 